\title{
The Palaeolithic Exploitation of the Lithic Raw Materials and the Organization of Foraging Territory in Northeastern Japan
}

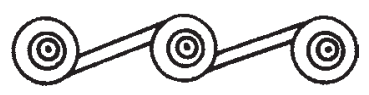

\author{
KOHTARO YOSHIKAWA
}

\section{INTRODUCTION}

Since the BeginNing of PAlaeOlithic ReSEArCh in 1949 (Sugihara 1956), Japanese archaeologists have been mainly interested in the relationship between lithic typology and technology. Only recently have they come to pay more attention to the behavioral and organizational domains of analysis, including issues concerning mobility of foraging groups and foraging territories. In the Kanto region, central Honshu, progressive Palaeolithic researches have been conducted and some studies have focused on the exploitation of various sources of lithic raw materials and the organization of foraging territory (e.g., Kunitake 2005). In contrast, very few attempts have been made to carry out this type of behaviorally focused archaeological research in northeastern Japan (specifically the Tohoku region).

This article explores the organization of foraging territories among early Upper Palaeolithic (EUP) groups in northeastern Japan (Fig. 1). In this article, a "foraging territory" is a spatial residential area in which human groups exploit (i.e., procure and consume) various resources, based on a similar mobile strategy. In northeastern Japan, there are coastal areas (lowlands) and mountainous areas (uplands), both of which run from north to south in parallel and have differing ecological characteristics. Despite such geological restrictions, I predict that the size and the relation of foraging territory were not unchangeable during the Upper Palaeolithic. Environmental fluctuations and social demands for various resources influence foragers to "reorganize" their mobile territories. In this article, I examine the relations between these spatial areas and foragers, considering how foraging territories are "organized" by human groups and whether they develop trade relationships between territories, from the viewpoint of exploitation of lithic raw materials.

Theoretically, Palaeolithic forager territoriality is strongly tied to the organization of procurement and consumption behavior, as evidenced in food remains and lithic raw materials. Unfortunately, it is very rare to obtain hard evidence for consumed food resources, because few animal fossils are associated with archaeological remains 


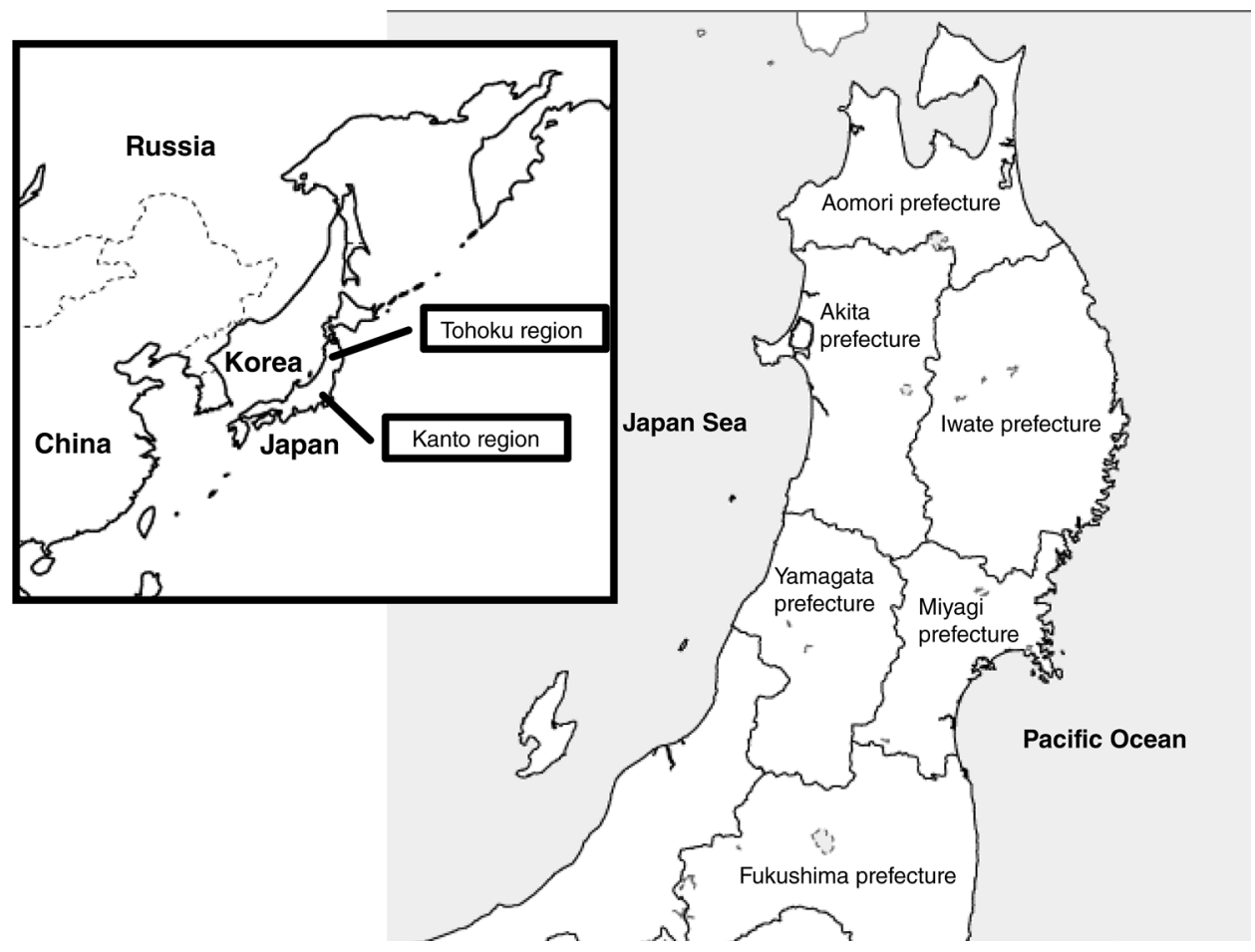

Fig. 1. Locations in Japan and northeastern Japan (the Tohoku region), consisting of six prefectures.

in Japanese Palaeolithic sites. Stone hunting weapons are frequently the only material reflection of aspects of food-procurement strategies. This article discusses the role of trapezoids and knife-shaped blades (Fig. 2) as the dominant classes of EUP chipped stone tools that can inform our understanding of food procurement strategies among Upper Palaeolithic foragers in northeastern Japan.

My examination of these lithic materials focuses on morphology, manufacturing technology, and levels of technological investment in the production of trapezoids and knife-shaped blades. The results of this analysis provide significant insights into Palaeolithic food-procurement strategies in northern Japan.

The study of the exploitation of lithic materials is one of the important research domains for understanding the nature of foraging territories. In the course of prehistory in northern Japan (i.e., Palaeolithic, Jomon, and Yayoi periods), almost all chipped stone tools were made from siliceous shale, which is locally available (Yoshikawa 2008). Determination of lithic resource provenance is a critical topic and popular research methodology in examining variability in human exploitation of lithic materials. Despite technical progress in geochemical determination of lithic material provenance, the application of reliable methods to locate the origin of sedimentary rocks, unlike volcanic rocks (e.g., obsidian; Shackly 1998), is still underdeveloped. Despite this problem, empirical studies show that Palaeolithic foragers in the region likely procured raw materials nearby their sites, because siliceous shale is available everywhere in northeastern Japan. Each source of siliceous shale manifests differences in quality, texture, and color (Hata 1998). Differences in siliceous shale can also be easily seen 

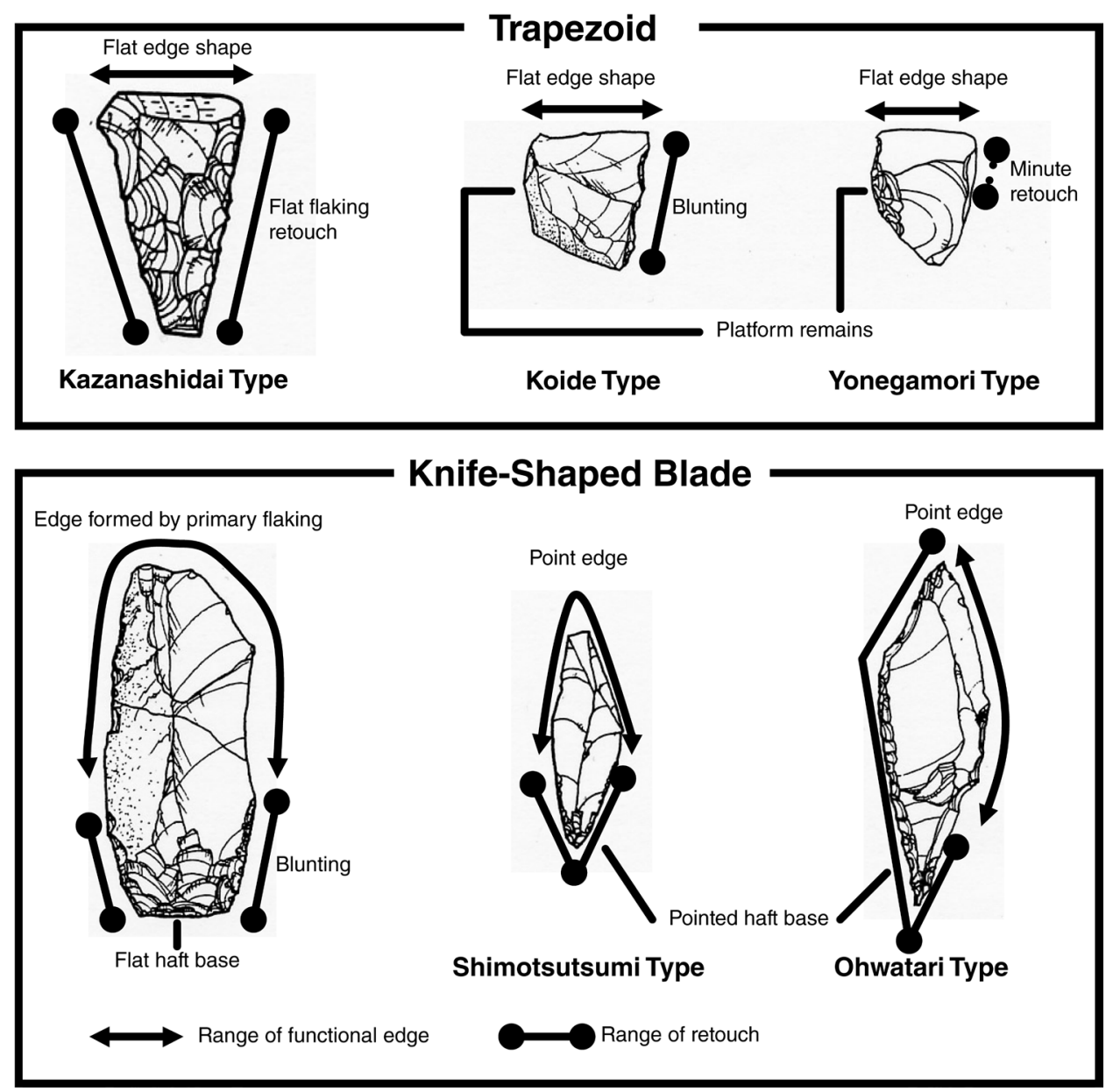

Fig. 2. Types of trapezoids and the knife-shaped blades.

macroscopically, and a visual observation can roughly indicate the individual characteristics of siliceous shale resources due to a pronounced variety of quality and color (see below). In the analysis of tools and debris in the lithic assemblages, I particularly examine variation in the size and quality of procured lithic materials, and how Palaeolithic foragers in the site consumed them. The results provide indications of how Palaeolithic foragers organized mobility strategies in their territories in relation to food procurement.

Cultural-stratigraphic studies in the Kanto region have shown that there were several cultural periods in the EUP (Oda and Keally 1979; Suzuki 2001). Despite the well-established cultural sequences of lithic industries, researchers have rarely discussed the kinds of human behavioral and environmental factors responsible for changes in characteristics of lithic assemblages. Although relationships between environmental fluctuations and human activities have not been commonly investigated, it is likely that some aspects of environmental change (e.g., shifts in climatic conditions and biotic reorganization) could have had significant impacts on the organization of 
human activities (Riel-Salvatore and Barton 2004). Specifically, territories of mobile foragers may have been transformed in response to environmental changes. In order to discuss these potential impacts on forager territorial organization, I preface my analysis with a discussion and clarification of the cultural chronology of EUP in northeastern Japan.

Firstly, I propose several chronological stages of the EUP in northeastern Japan with reference to the established chronology in the Kanto region, defining the predominant lithic types (trapezoids and knife-shaped blades) by analyzing the tool forms and technology in assemblages. Secondly, I divide the Tohoku region into two areas: the coastal area of the Japan Sea and the Ohu Mountains area, and in each area I classify various sites into four or five types, examining the tool type composition, the production sequences of chipped stone tools, and the availability and procurement of lithic raw materials, based on chronology. I propose that these site types attributed to each chronological stage reflect the differing functions of site and foraging strategies. Lithic source provenance studies are also important to reconstructing Palaeolithic foraging strategies and territories (Jones et al. 2003). For these comparisons, it is necessary to carry out an explicit examination of refitting studies (Serizawa 1978), and Minimal Analytical Nodule Analysis (MANA: Andrefsky 2009; Larson and Kornfeld 1997; Tozawa et al. 1974) among the assemblages. Here is an overview of how foragers procured and consumed their lithic raw materials in each area for the manufacturing they required from the viewpoint of lithic provenance sources. Thirdly, I discuss exploitation of lithic raw materials and foraging territories in each chronological stage with a description of characteristics of both areas. Lastly, this article explores the organization of mobile territory as rational behavior engaged in by a social group and the interactions of foraging groups, and provides insights into how early Palaeolithic foragers in northeastern Japan organized their movements and activities within their territories.

\section{THE CHRONOLOGY OF THE EARLY UPPER PALAEOLITHIC IN NORTHEASTERN JAPAN}

The Tohoku region of northern Japan is generally divided into three geographic areas: the Japan Sea coastal area, the Ohu Mountains area, and the coastal area along the Pacific Ocean (Fig. 3). Most Palaeolithic sites are distributed in the western half of the Tohoku region, the Japan Sea area and the Ohu Mountains area, and this article focuses on the assemblages found in these two areas (Table 1).

In the Tohoku region (northern Honshu), loam which accumulated during the Late Upper Pleistocene formed sediments, but not in sufficient thickness to investigate changes of assemblages through well-stratified deposits, in contrast to the Kanto region (Fig. 4). This handicap makes it difficult for researchers to establish chronostratigraphy in the Tohoku region. Although there are some chronologies in this region (Fujiwara and Yanagida 1991; Sato 1992), there is little agreement on how the assemblages changed during the EUP.

By way of discussing the chronology and the technology, trapezoid and knifeshaped blades are the major types of characteristic early Upper Palaeolithic tools. Before directly addressing the issue of chronology, it is necessary to briefly discuss the definition of trapezoids (Oda 1969, 1977; Sato 1988) and knife-shaped blades (i.e., backed blades; Serizawa 1978) as chronological markers in Japanese archaeology. Trap- 


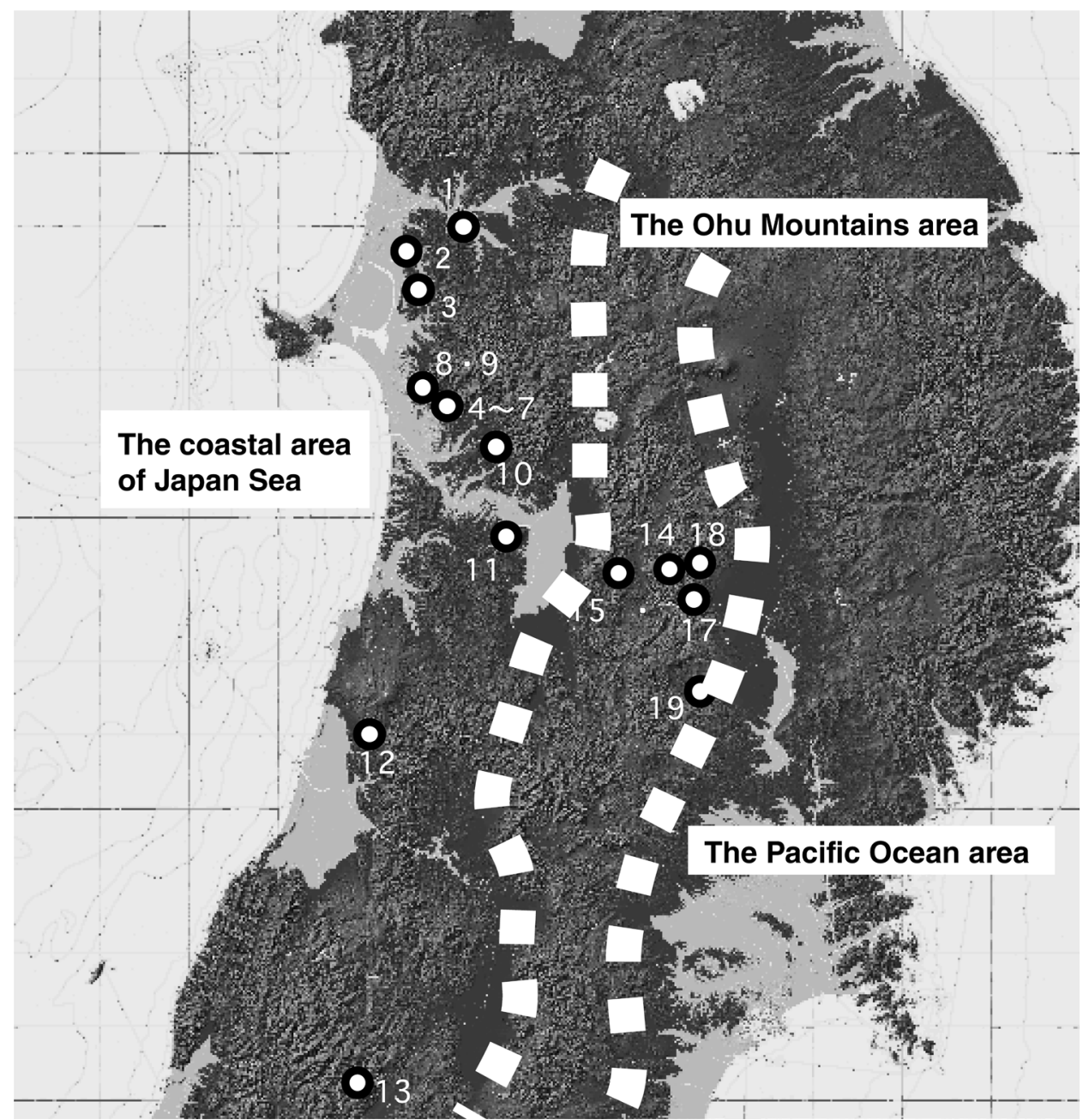

Fig. 3. Site locations in the Tohoku region. Numbers match site numbers in Table 1.

ezoids are seen as a defining feature of the early Upper Palaeolithic in Japan. Similarly, knife-shaped blades are characteristic tools of the period, but continue on into the late Upper Palaeolithic. Japanese Palaeolithic archaeologists have consistently relied on these tools for reconstructing cultural stages or interpreting activities at sites through the analysis of morphologies, formal types, technologies, and functional relations between trapezoids and knife-shaped blades.

Trapezoids and knife-shaped blades were manufactured through retouching on flakes or blades, with the former generally created from various flakes and the latter generally from blades. The kinds of retouch technique for these tools include flat flaking, minute flaking, and a blunting technique, and both types are characterized by sharp edges made through primary flaking. Because of these similarities in production, some archaeologists think that trapezoids should be included in a large category of knife-shaped tools. Trapezoid can be defined as a chipped stone tool that has a sharp 


\begin{tabular}{|c|c|c|c|c|c|c|c|c|c|c|c|c|c|c|c|c|c|c|c|c|}
\hline 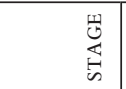 & 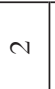 & 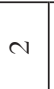 & $\sim$ & -1 & - & -1 & - & - & $m$ & $m$ & N & $m$ & $N$ & $\sim$ & $m$ & $n$ & - & $N$ & - & 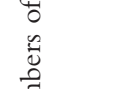 \\
\hline 岂薬 & $u$ & $\cup$ & A & $\infty$ & $\varangle$ & $\varangle$ & 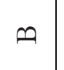 & $\varangle$ & 띠 & 디 & $u$ & 띠 & D & 0 & $山$ & 山 & $\infty$ & $u$ & $\varangle$ & $\vec{\Xi}$ \\
\hline $\begin{array}{l}z \\
8 \\
0\end{array}$ & - & $\mathrm{N}$ & 0 & - & - & - & - & 0 & 0 & 0 & N & 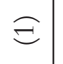 & - & - & 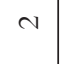 & t & $\vec{m}$ & Ð & $v$ & ن \\
\hline 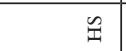 & & & $m$ & & - & & & 0 & 0 & & & & & - & - & 6 & 12 & & & こँ \\
\hline$\frac{x}{4}$ & & - & & - & & & & 0 & & & - & & & & & & $\because$ & 0 & - & $\tilde{\Xi}$ \\
\hline$\approx$ & \pm & & 仝 & 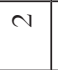 & in & $\sigma$ & & & & & $N$ & & & - & - & - & \begin{tabular}{l|} 
\\
$\infty$ \\
$\infty$
\end{tabular} & 0 & & ఫ్ \\
\hline 喾 & - & & & & & & & & & & 10 & & & & & & & 0 & & \\
\hline 吕 & in & - & + & & & & - & & & 0 & - & & & & in & in & & 0 & - & \\
\hline$u$ & $\stackrel{20}{2}$ & & $\nabla$ & $a$ & ङ & $\exists$ & $m$ & 0 & & 0 & $m$ & - & 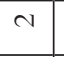 & - & $m$ & $\stackrel{2}{2}$ & & 0 & 9 & 气̃ \\
\hline$\approx$ & t & $\begin{array}{c} \\
\end{array}$ & $\begin{array}{ll}\infty \\
\infty \\
\infty\end{array}$ & in & 宮 & $\bar{n}$ & & O & O & O & 3 & $r$ & & $\infty$ & $\mathrm{N}$ & & & O & ป & $\ddot{x}$ \\
\hline $\mathrm{z}$ & in & I & 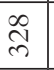 & $\stackrel{0}{0}$ & & & लै & 0 & 0 & 0 & 0 & - & in & 10 & $\exists$ & $\stackrel{\infty}{\sim}$ & - & 0 & & \\
\hline 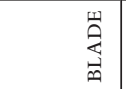 & \multirow{3}{*}{$\begin{array}{l}\infty \\
\infty \\
\infty\end{array}$} & 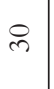 & $\stackrel{0}{+}$ & \multirow{4}{*}{$\stackrel{\infty}{\stackrel{\infty}{\sigma}}$} & \multirow{4}{*}{$\begin{array}{l}\widehat{a} \\
\text { ते } \\
d\end{array}$} & \multirow{4}{*}{$\stackrel{\stackrel{\Im}{+}}{\sim}$} & \multirow{3}{*}{$\begin{array}{l}\stackrel{\Xi}{\Xi} \\
\stackrel{\Xi}{\rightleftarrows}\end{array}$} & \multirow{4}{*}{0} & \multirow{4}{*}{0} & \multirow{4}{*}{0} & & $\stackrel{\infty}{+}$ & 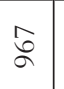 & $\infty$ & \pm & $\vec{m}$ & & & & \\
\hline 面 & & \multirow{2}{*}{ 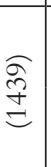 } & \multirow{2}{*}{$\begin{array}{l}\hat{a} \\
\text { ò } \\
\text { a }\end{array}$} & & & & & & & & \multirow{2}{*}{ 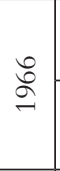 } & 0 & & $\widehat{\sigma}$ & 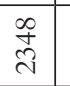 & $\begin{array}{l}\text { ले } \\
\infty \\
i n\end{array}$ & $\stackrel{m}{=}$ & 0 & $\stackrel{\sim}{q}$ & 总 \\
\hline 焉 & & & & & & & & & & & & $\stackrel{\text { 卓 }}{+}$ & $\stackrel{+}{\sim}$ & $\frac{10}{R}$ & & $\infty$ & & & & $\simeq$ \\
\hline 㟧 & ते & $\stackrel{\overparen{10}}{ \pm}$ & $\stackrel{m}{\pi}$ & & & & $\hat{\imath}$ & & & & $\stackrel{?}{q}$ & $a$ & $\bar{m}$ & $\mathrm{~N}$ & & & if & 0 & $\widehat{\sigma}$ & \\
\hline 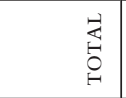 & ले & $\begin{array}{l}\overparen{g} \\
\stackrel{2}{Ð}\end{array}$ & 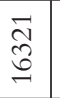 & $\overrightarrow{\overrightarrow{\widehat{V}}}$ & $\begin{array}{l}\text { aे } \\
0 \\
\text { dิ }\end{array}$ & $\begin{array}{l}8 \\
\stackrel{2}{n} \\
\text { n }\end{array}$ & $\begin{array}{l}\approx \\
\stackrel{\alpha}{\approx}\end{array}$ & & & & 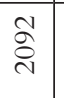 & $\begin{array}{l}\widehat{O} \\
\stackrel{d}{0}\end{array}$ & तิ & in & $\begin{array}{l}10 \\
\infty \\
\approx \\
\end{array}$ & $\begin{array}{l}\text { तิ } \\
\text { in }\end{array}$ & 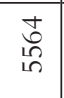 & $\begin{array}{l}\infty \\
\stackrel{i}{0} \\
\stackrel{2}{0}\end{array}$ & $\overline{\mathrm{m}}$ & 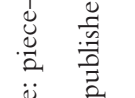 \\
\hline 葸䓢焉 & 尔 & ๗ै & $\stackrel{\leftrightarrow}{\sim}$ & I & q & ले & q & $\vec{m}$ & q & $\stackrel{R}{R}$ & $\hat{\sigma}$ & $\stackrel{8}{I}$ & 导 & $\stackrel{+}{े}$ & $\vec{\nabla}$ & $\overrightarrow{\mathrm{d}}$ & $\stackrel{t}{\ominus}$ & $\stackrel{\circ}{\sim}$ & 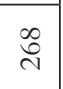 & 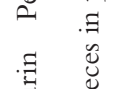 \\
\hline 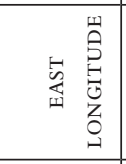 & $\begin{array}{l}0 \\
8 \\
0 \\
8 \\
0 \\
+ \\
-1\end{array}$ & 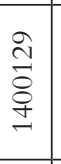 & $\begin{array}{l}\infty \\
0 \\
0 \\
8 \\
8 \\
+ \\
-1\end{array}$ & \begin{tabular}{l}
8 \\
8 \\
$\stackrel{0}{0}$ \\
\multirow{2}{+}{} \\
$=$
\end{tabular} & $\begin{array}{l}8 \\
8 \\
0 \\
\vdots \\
+ \\
\end{array}$ & 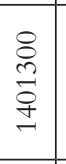 & $\begin{array}{l}8 \\
\stackrel{8}{+} \\
\stackrel{5}{9} \\
-1\end{array}$ & $\begin{array}{l}\infty \\
\stackrel{1}{1} \\
\stackrel{8}{o} \\
\stackrel{0}{q}\end{array}$ & $\begin{array}{l}\vec{f} \\
\dot{8} \\
\dot{8} \\
\end{array}$ & $\begin{array}{l}\hat{i n} \\
\stackrel{n}{v} \\
\stackrel{\delta}{q}\end{array}$ & 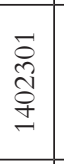 & & & & & & & & & 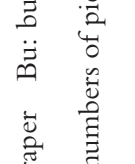 \\
\hline 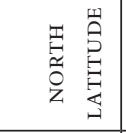 & 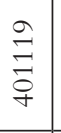 & $\begin{array}{l}\stackrel{q}{q} \\
\stackrel{8}{o} \\
\stackrel{+}{+}\end{array}$ & $\begin{array}{l}\text { ̀े } \\
\text { } \\
\stackrel{+}{+}\end{array}$ & $\begin{array}{l}8 \\
\infty \\
\approx \\
\approx \\
\approx\end{array}$ & $\begin{array}{l}8 \\
\infty \\
\approx \\
\approx \\
\approx\end{array}$ & $\begin{array}{l}8 \\
\infty \\
\stackrel{2}{~} \\
\end{array}$ & $\begin{array}{l}\stackrel{\vdots}{\alpha} \\
\text { ळे }\end{array}$ & 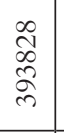 & $\begin{array}{l}\frac{1}{2} \\
\text { ळे } \\
\text { }\end{array}$ & $\underset{\infty}{\stackrel{2}{\approx}}$ & $\begin{array}{l}\vec{\sigma} \\
\infty \\
\\
\text { ले }\end{array}$ & & & & & & & & & 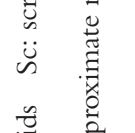 \\
\hline 愙 & 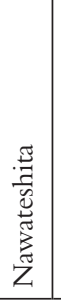 & 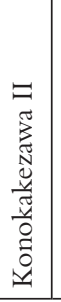 & 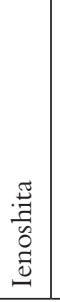 & 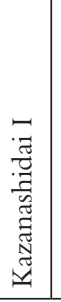 & 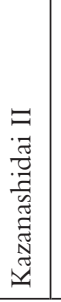 & 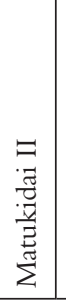 & 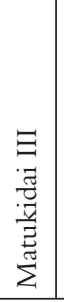 & $\begin{array}{l}\overline{0} \\
\overline{0} \\
\overline{0} \\
\stackrel{N}{N} \\
\end{array}$ & 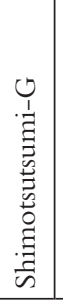 & 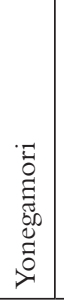 & 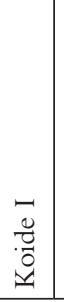 & $\begin{array}{l}\frac{1}{1} \\
\bar{y} \\
0 \\
0 \\
0 \\
0 \\
0 \\
0 \\
0 \\
0 \\
0 \\
\\
\end{array}$ & 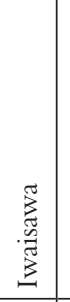 & 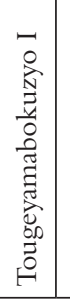 & 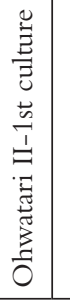 & 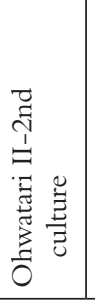 & 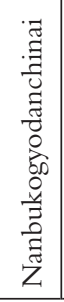 & 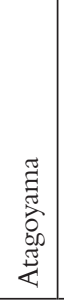 & 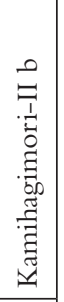 & 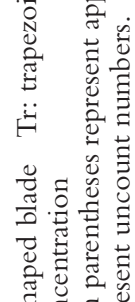 \\
\hline 苗 & & & & & & вәле & [e]seo & & & & & & & & & 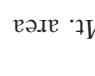 & & & &. \\
\hline$\dot{\dot{z}}$ & - & N & $n$ & + & in & 0 & $r$ & $\infty$ & $a$ & $\stackrel{\circ}{\sim}$ & $\exists$ & $\stackrel{1}{\sim}$ & $\stackrel{2}{2}$ & \pm & $\stackrel{20}{\sim}$ & 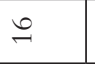 & $\approx$ & $\stackrel{\infty}{\sim}$ & 2 & \\
\hline
\end{tabular}




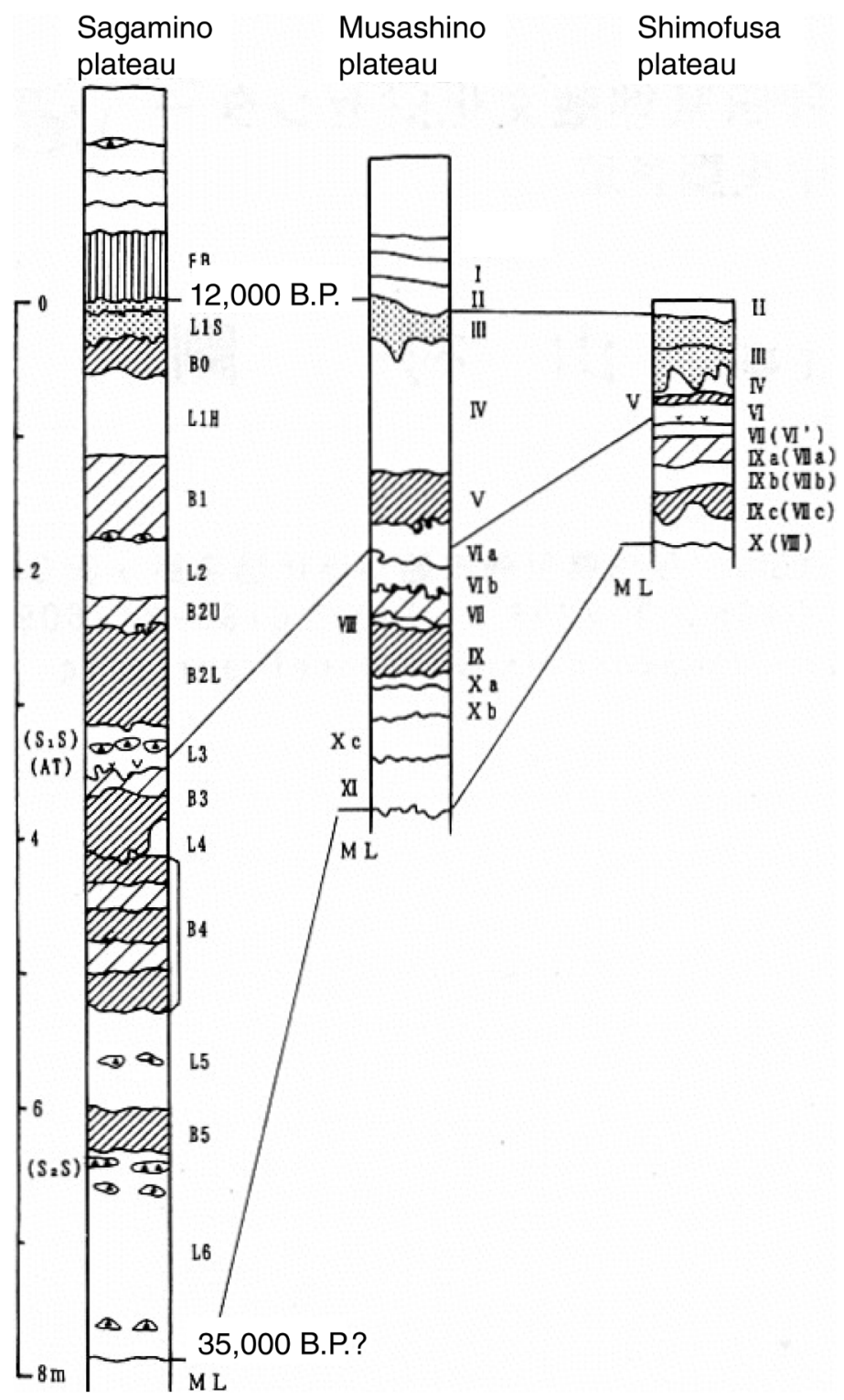

Fig. 4. Standard lithostratigraphic sequences compared among three major plateaus in the Kanto region.

edge at right angles to the retouched edge (Fig. 2). A knife-shaped blade is a pointed stone tool that has a sharp edge and blunting edges (Fig. 2).

Beyond their role as chronological markers, the ubiquity of trapezoids and knifeshaped blades can inform us about forager subsistence strategies through interpretations of function. Researchers have attempted to infer stone tool function by microwear analysis or experimental archaeology. Although functional interpretations are still controversial, almost all knife-shaped tools can be recognized at least as some type of spearhead. Some trapezoids also seem to be a part of spear kits, with clear haft bases. 
Other types of small rectangular trapezoids can only be assumed in general by archaeologists to be part of composite tools, since these trapezoids are not found with hafts. In this article, I recognize trapezoids and knife-shaped blades as hunting weapons, as they both appear to represent component parts of a spear.

Among the other regions, I have suggested three cultural-chronological stages of the EUP in northeastern Japan (Yoshikawa 2008; see below), in concert with the chronological framework in the Kanto region (Fig. 5):

Chronological Stage 1: This stage is represented by trapezoids retouched by a flatflaking technique and large knife-shaped blades retouched through the minuteflaking technique (Fig. 6).

Chronological Stage 2: This stage has both the trapezoids and knife-shaped blades (both retouched by a blunting technique). These two classes of chipped stone tools are often associated together in assemblages (Figs. 6, 7).

Chronological Stage 3: This stage is characterized by trapezoids retouched by minuteflaking technique and knife-shaped blades retouched by intensive-blunting technique. Both tools are often found together in an assemblage (Fig. 7).

In Chronological Stage 1, the morphological difference between trapezoids and knife-shaped blades is subtle. For instance, there are similarities in morphology, especially in edge shape. The only prominent difference is found in their manner of retouch: the trapezoids were retouched by flat flaking, while the knife-shaped blades were retouched by minute flaking. The amount of effort expended to retouch trapezoids is significantly greater than that of knife-shaped blades, based on the observations of the extent of retouching. I have designated the trapezoids with the flat-flaking retouch as the Kazanashidai type (Fig. 2). Trapezoids and knife-shaped blades are found in different sites, suggesting that these tool classes were produced and discarded at different locations (Table 1). The alternative production and discard of tools would have been the result of difference in site functions.

In Chronological Stage 2, morphological and functional distinction between trapezoids and knife-shaped blades is clear. In both cases, the blunting technique is used not only to shape knife-shaped tools, but also to make trapezoids. The efforts expended to make retouches on tools should be equivalent between these two classes of tool. Trapezoids made on rectangular flake blanks with blunting are called the Koide type (Fig. 2), while trapezoids made on seashell flake blanks by minute retouch are called the Yonegamori type (Fig. 2). These trapezoids and knife-shaped blades were found in association and they were occasionally made from an identical nodule of raw material. It should be noted, however, that all knife-shaped blades were transported into the Nawatesita site: almost all trapezoids were produced in this site. This fact suggests that the manufacturing locations of both tools did not coincide perfectly with each other.

In Chronological Stage 3, the number of sites is small, diminishing significantly from Stage 2. Trapezoids and knife-shaped blades are morphologically distinguished, similar to the Chronological Stage 2. Trapezoids are minutely retouched, while in contrast knife-shaped blades are blunted intensively. The physical extent of retouch is the most extensive found among the three chronological stages. This indicates that the effort expended for making knife-shaped blades was larger than that of trapezoids. Both knife-shaped blades and trapezoids were produced at almost all sites. The size of knife-shaped blades had been miniaturized in the coastal area of the Japan Sea. In contrast, the size of knife-shaped blades became larger, while trapezoids disappeared 


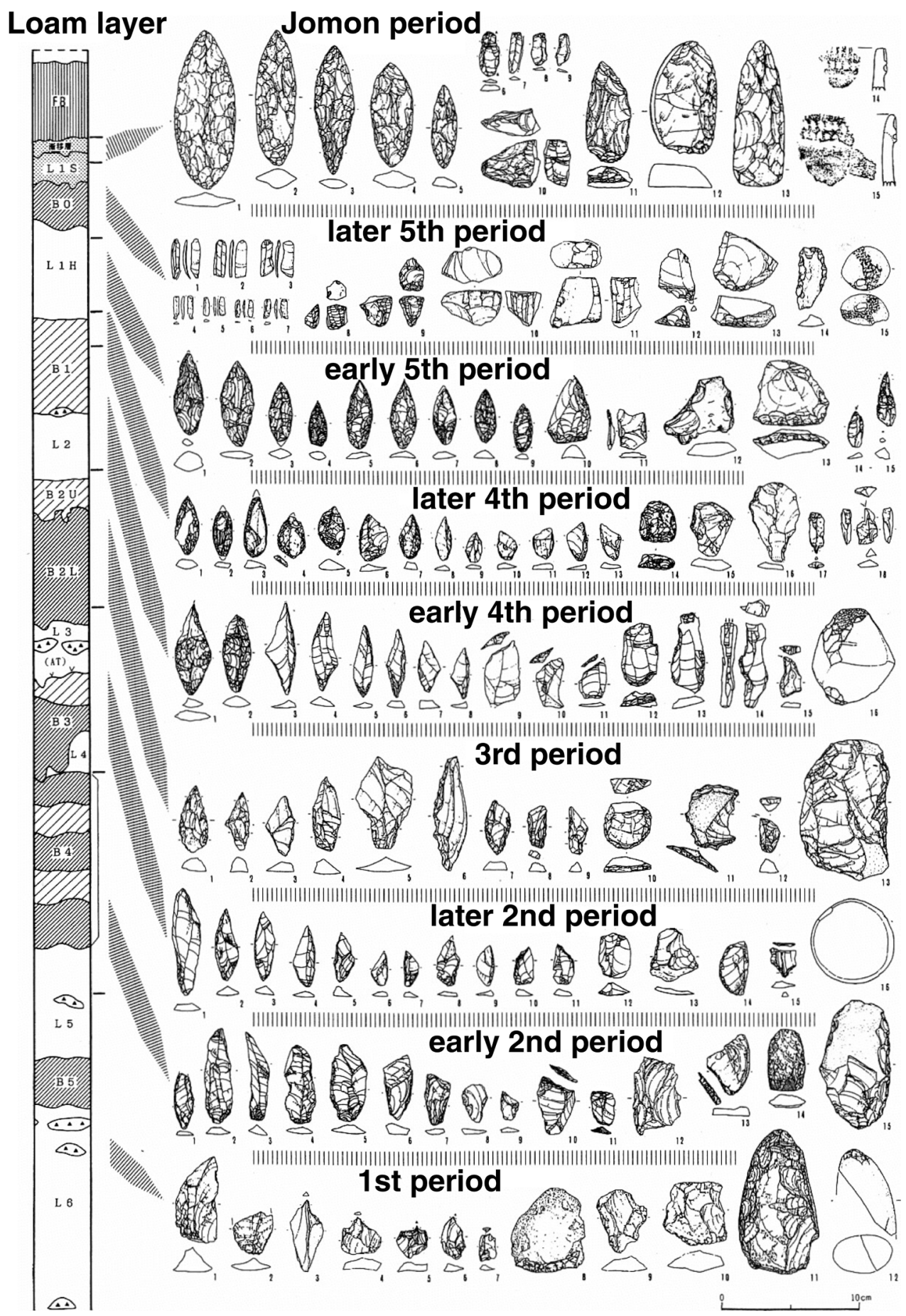

Fig. 5. Chronology of Upper Palaeolithic assemblages in the Kanto region (Suzuki 2001). 


\section{Stage 1}

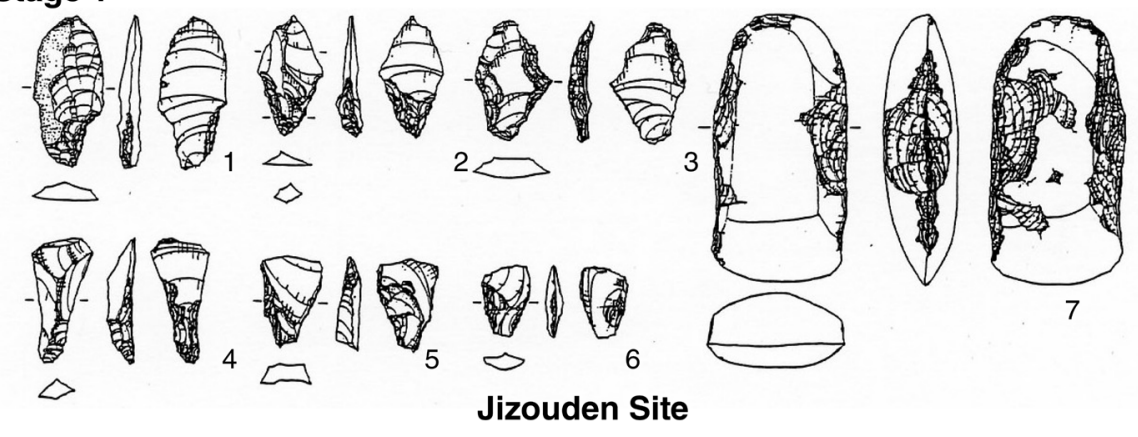

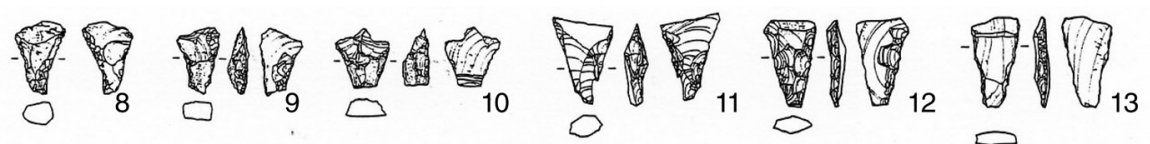

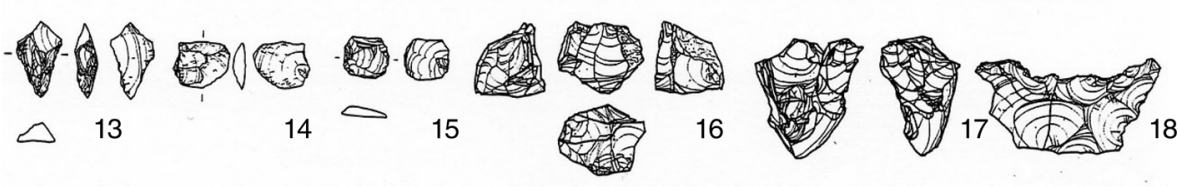

Kazanashidai-2 Site
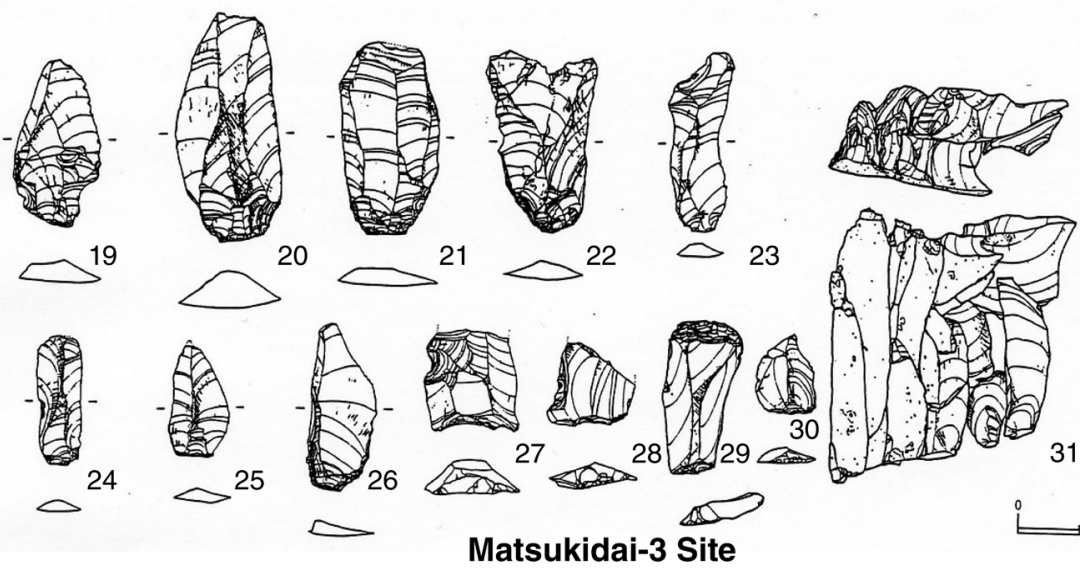

\section{Stage 2}

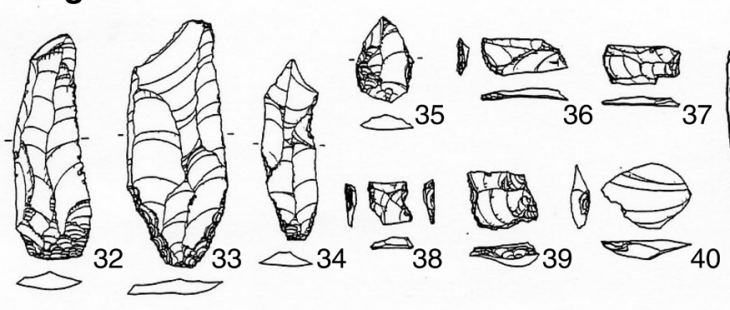

Koide-1 Site

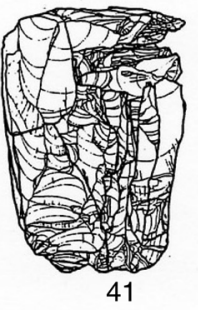

41
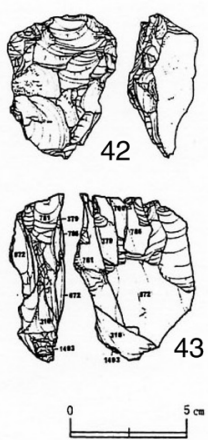

1-6, 8-15, 36-40: trapezoid, 7: edge-polished axe, 19-26, 32-35: knife-shaped blade, 27-30: end scraper, 16-18, 31, 41-43: refitting material (especially 31,41 and 43 represent blade technique)

Fig. 6. EUP lithic assemblages in the Japan Sea coastal area (stages 1 and 2). 


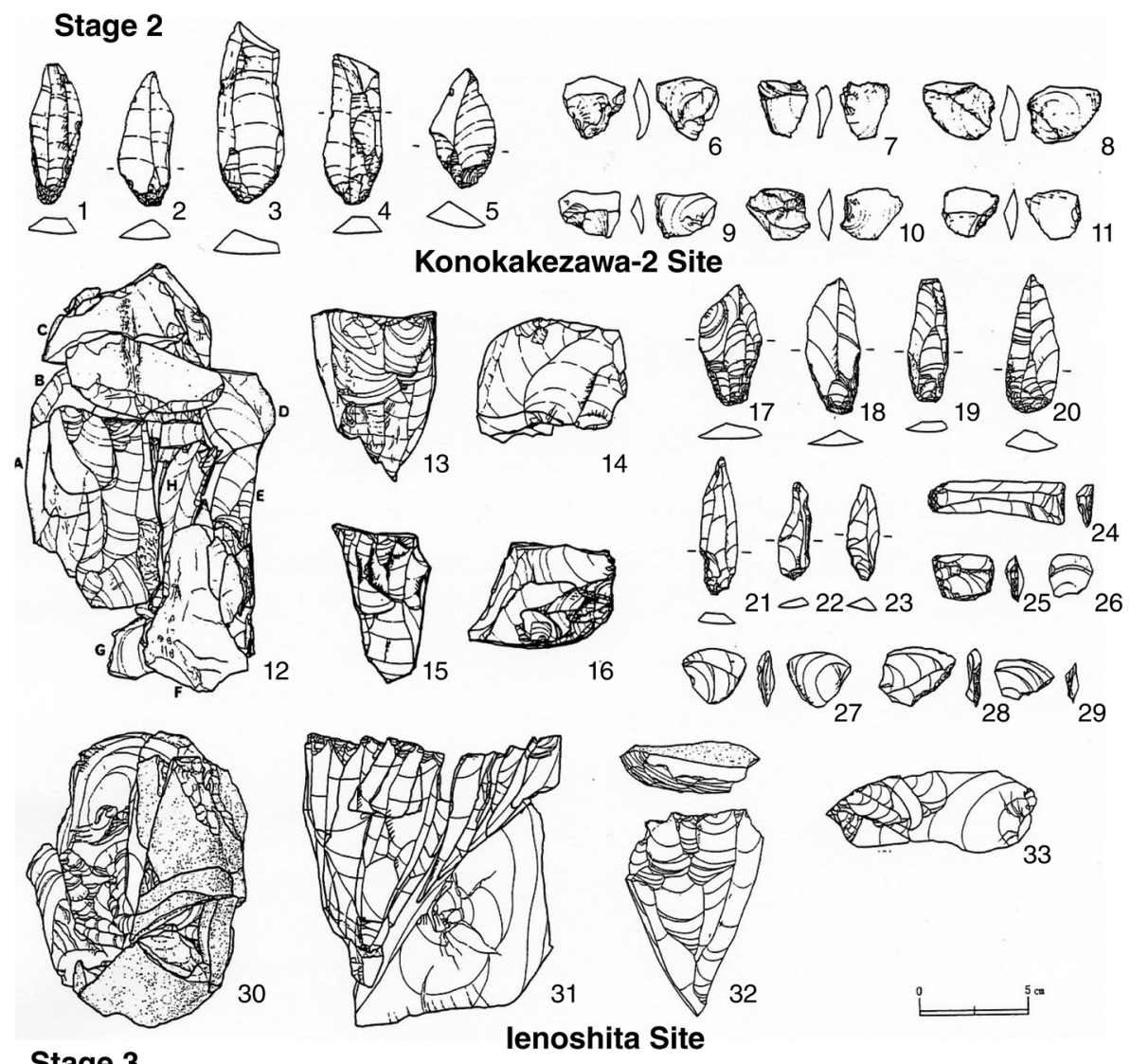

Stage 3

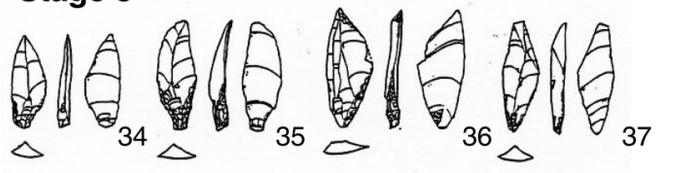

1-5, 17-23, 34-39, 44-49: knife-shaped blade 6-11, 25-29, 40-43, 50-53: trapezoid

12-16, 30-33: refitting material

(t)

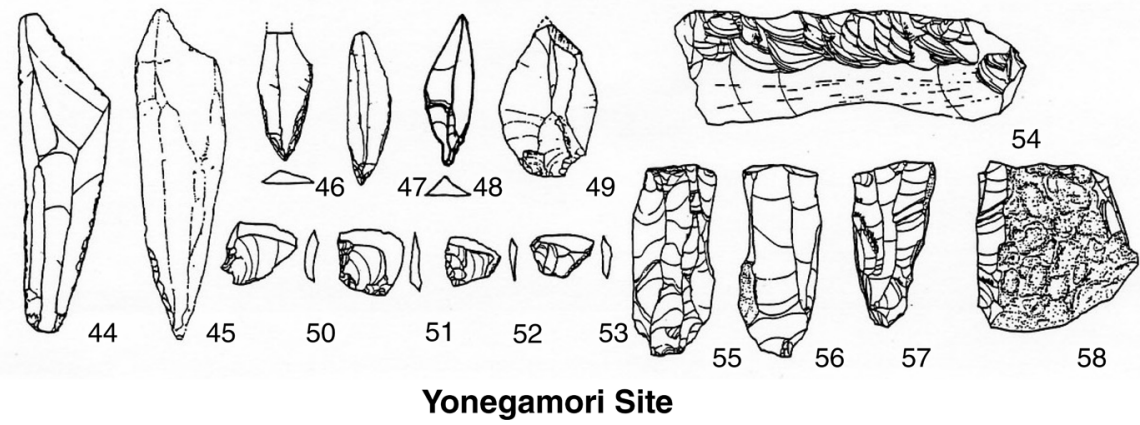

Fig. 7. EUP lithic assemblages in the Japan Sea coastal area (stages 2 and 3). 


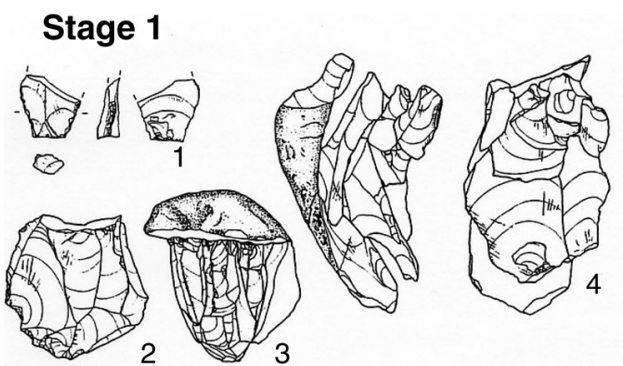

Nanbukogyodanchi Site

Stage 2
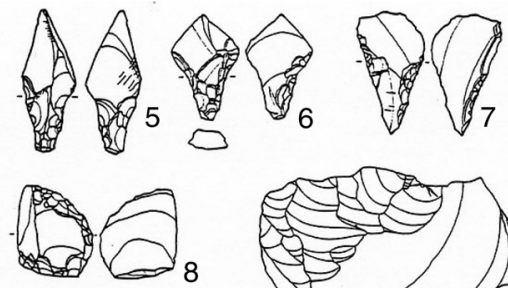

9

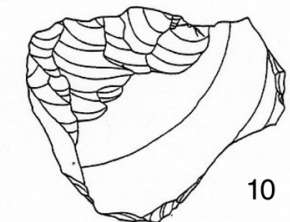

Kamihagimori Site
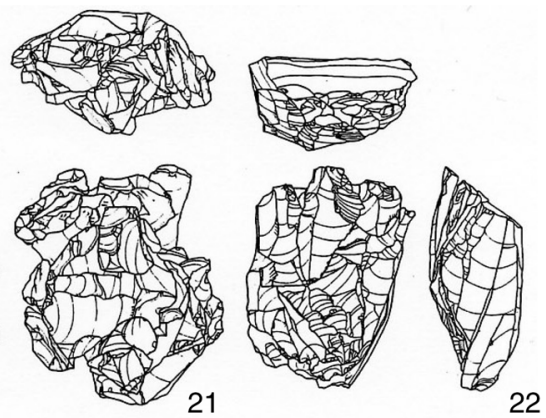

Tougeyamabokuzyo Site

\section{Stage 3}
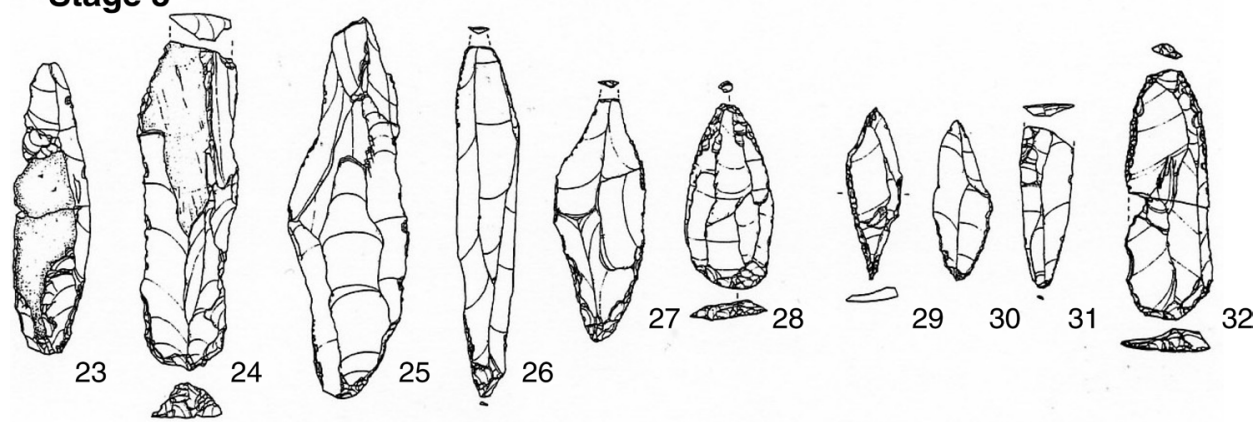

\section{Ohwatari-2 Site}

1, 11-13, 23-31: knife-shaped blade, 5-9, 14-20: trapezoid, 2, 10: core, 3-4, 21-22: refitting material

Fig. 8. EUP lithic assemblages in the Ohu Mountains area (stages 1 to 3).

in the Ohu Mountains area (Fig. 8). The miniaturized knife-shaped blades characterized by pointed hafts are called the Shimotsutsumi type (Fig. 2) and this type of tool is widely found along the coastal area of the Japan Sea. The large knife-shaped blades with pointed hafts are called the Ohwatari type (Fig. 2) and are distributed in the Ohu Mountains area.

The variability in the morphology of stone tools, lithic composition, and technological sequences described above are clearly related to variability in lithic sources 
and the exploitation strategies of Palaeolithic foragers. In the following section, I examine how this exploitation of lithic raw materials changed in different chronological stages.

THE EXPLOITATION OF LITHIC RAW MATERIALS IN COASTAL AREAS OF THE

$$
\text { JAPAN SEA }
$$

The coastal area of the Japan Sea is known as a region of high-quality siliceous shale that is more abundant than that of the Ohu Mountains area. The shale in this coastal area is more silicified and shiny than that of the Ohu Mountains area, and almost all of the chipped stone tools (more than 90 percent) in assemblages in the coastal area of the Japan Sea were made from this high-quality siliceous shale. Other lithic raw materials include obsidian and chert, although they are not as abundant as siliceous shale. Archaeologists empirically distinguish lithic resources between the coastal area and the mountains based on their visual characteristics. The siliceous shale in the coastal area is appropriate for knapping stone tools because of its high quality. The cortical surface of siliceous shale artifacts suggests that they were made from round pebbles with water-rolled cortex, indicating that the materials were procured along river systems. The Palaeolithic foragers in the coastal area presumably procured raw materials in the form of siliceous shale from riverbeds near their sites. Riverbeds, as secondary depositional contexts, are largely composed of materials that were eroded from a primary exposure and transported downstream for redeposition.

Thirteen sites with EUP assemblages were found along the coastal area (Fig. 3, Table 1), located on the Pleistocene river terraces, with the size of the artifact assemblages varying from 330 artifacts in the smallest to 16,321 in the largest. These assemblages include both tools and debris that were the refuse remains of lithic reduction. Analysis of debris plays an important role in understanding variability in lithic procurement and consumption. We can develop a better understanding of the variation in the lithic raw materials that were conveyed into sites and consumed in tool production by Palaeolithic foragers through the methodological approaches of debris analysis, refitting analysis (Serizawa 1978), and minimal analytical nodule analysis (Larson and Kornfeld 1997; Tozawa et al. 1974). The results of these analyses suggest that foragers carried all classes of lithic debris (cores, flakes, and blades), chipped stone tools, and manuports (stone pebble) into all of the sites (Table 1). The various types of trapezoids and knife-shaped blades were produced during these consumption processes at each site. Here I categorize the EUP sites into five classes, based on the extent to which different types of stone tools were produced in each site (Table 1):

Site Type A: The sites in which Kazanashidai-type trapezoids were produced intensively; included are the Jizouden site, Kazanashidai-2 site, and Matsukidai-2 site.

Site Type B: The sites in which knife-shaped blades were produced intensively; included are the Kazanashidai-1 site and Matsukidai-3 site.

Site Type C: The sites in which Koide-type and Yonegamori-type trapezoids were produced in significant quantities, while knife-shaped blades were only occasionally produced; these include the Nawateshita site, Konokakezawa-2 site, and Koide-1 site.

Site Type D: The sites in which knife-shaped blades and Koide-type and Yonegamoritype trapezoids were all produced intensively; these include the Ienoshita site and Iwaisawa site. 
Site Type E: The sites in which both Shimotsutsumi-type knife-shaped blades and Yonegamori-type trapezoids were produced; these include the Simotsutsumi-G site, Yonegamori site, and Futokoronouchi-F site.

Considering the range of tool types and the lithic technology in the assemblages against a time scale, these site categories are correlated to distinct chronological stages in the framework for the EUP presented above: Site Type A and Site Type B belong to Chronological Stage 1, Site Type C and Site Type D are assigned to Chronological Stage 2, and Site Type E correlates with Chronological Stage 3. The two site categories, Site Type A and Site Type B in Chronological Stage 1, suggest that the trapezoids and the knife-shaped blades were produced and discarded in separate locations in this period. Among the category of Site Type A, the Jizouden site is characterized by a circular lithic concentration. These circular lithic concentrations are the prominent site feature found during the EUP in the Japanese Islands. In Chronological Stage 2, the two site categories reflect two assemblage types that are different in the amounts of lithic reductions: the Ienoshita site, one of the D sites, also has circular lithic concentration (Fig. 9).

In contrast with the Chronological Stage 1 sites, all of the assemblages include knifeshaped blades and trapezoids. However, the Nawateshita site (Type C), for instance, has no evidence for the manufacture of knife-shaped blades, and we might surmise that the location in which knife-shaped blades were produced was provably restricted. At Chronological Stage 3 sites, large-scale sites shaped like a circular settlement, which were common in the previous chronological stage, have not yet been found.

From the results of debitage observations, refitting studies, and minimum analytical nodule analysis, it can be inferred that raw materials were brought to every site in each of the three chronological stages. All of the sites have good access to available and high-quality raw materials for tool manufacturing. In other words, lithic resources are abundant along the coast of the Japan Sea.

Differences in site categories during each chronological-cultural stage reflect the changes in raw materials exploitation strategies caused by environmental fluctuations and food-procurement activities. In Chronological Stage 1, two classes of sites with different functions are present: locations in which trapezoids were made, used and discarded, and those in which knife-shaped blades were consumed. This difference suggests that Palaeolithic foragers strictly distinguished use localities of these tool classes in their foraging. In addition, Japanese archaeologists generally see the lithic circular concentrations, represented by the Jizouden site, as seasonally concentrated settlements of human groups who were dispersed during other seasons (Fig. 10). In Chronological Stage 2, all sites have both trapezoids and knife-shaped blades. To account for this phenomenon simply, trapezoids made in all locations were regarded as expedient tools, while knife-shaped blades made in limited locations were curated tools (Binford 1977). I suggest that the importance of knife-shaped blades among foragers increased in comparison with Chronological Stage 1, and further that this implies a change in hunting tactics. In Chronological Stage 3, it is difficult to interpret the relationship among different assemblages, because the site numbers start to decrease. The changes in morphology and size of knife-shaped blades presumably reflect changing strategies of hunting animals and/or methods of hafting these tools to make spears.

Palaeolithic foragers in the coastal area of the Japan Sea could adapt to environmental fluctuations and changes in food-procurement strategies without significant constraints by their available lithic raw materials, because high-quality lithic resources are 


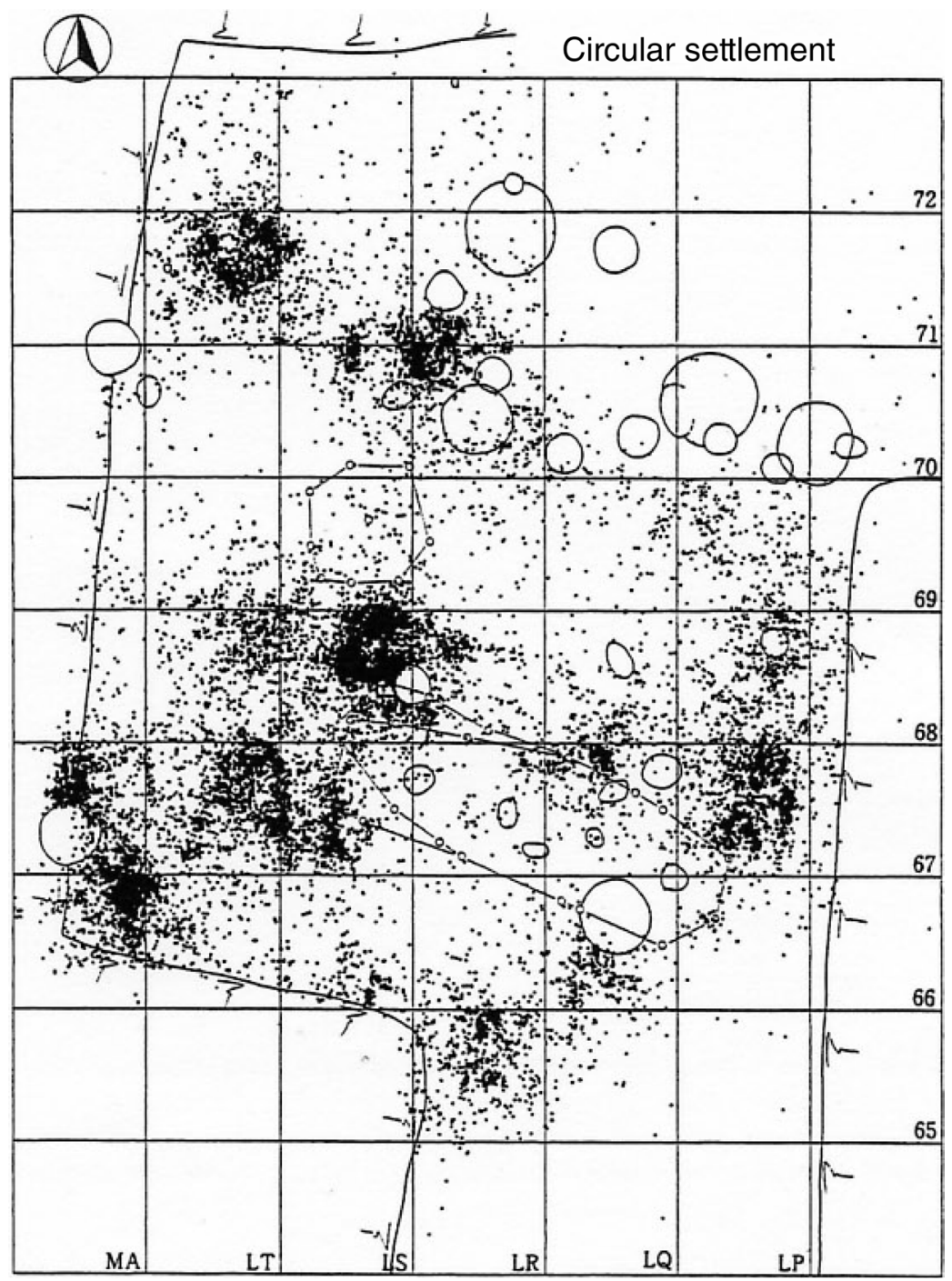

Fig. 9. Lithic circular concentration (the Ienoshita Site, Akita prefecture). Black dots represent locations of stone artifacts (tools and debris).

abundantly accessible in the region (Andrefsky 1994). The changes in site types and characteristics of assemblages directly indicate changes of lithic resource exploitation related to food-procurement strategy. However, we cannot fully construct a picture of Palaeolithic mobile territories in northeastern Japan solely through the analysis of sites in coastal areas where high-quality and abundant siliceous shale are available.

THE EXPLOITATION OF LITHIC RAW MATERIALS IN THE OHU MOUNTAINS AREA

The Ohu Mountains area is known as the provenance of siliceous shale with lower quality than that of coastal areas of the Japan Sea. A total of six assemblages dating to 


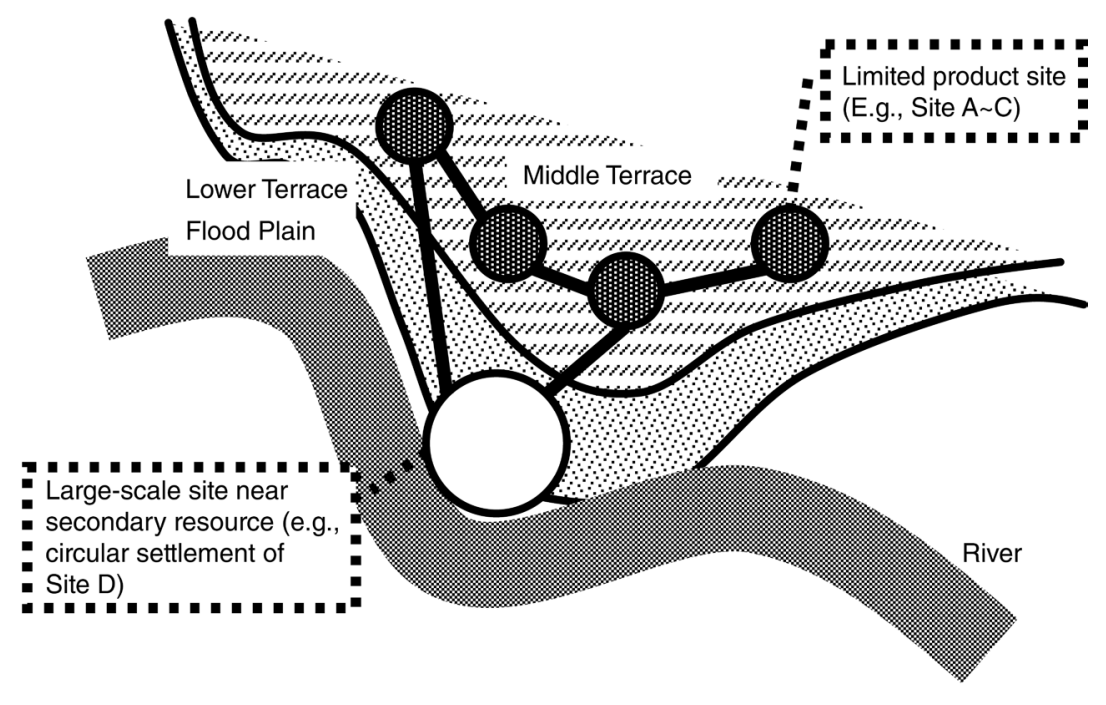

Fig. 10. Model of site connections between large-scale and small-scale sites (stages 1 and 2).

the early Upper Palaeolithic were found in the Ohu Mountains area (Fig. 3, Table 1). Almost all of the pieces (more than 90\%) in the assemblages were made of siliceous shale. Palaeolithic sites are distributed on river terraces created by the erosion and deposition of a vast river system. The characteristics of these assemblages and sites are similar to those of the coastal area of the Japan Sea.

Here, I categorize these sites based on the same methods used in the earlier section (Table 1):

Site Type A: The sites in which the Kazanashidai types were produced intensively; this includes the Kamihagimori site.

Site Type B: The sites in which knife-shaped blades were produced intensively; this includes the Nanbukogyodanchinai site.

Site Type C: The sites in which the Koide and Yonegamori types were produced frequently, with some knife-shaped blades; these include the Tougeyamabokuzyo-1 site and the Atagoyama site.

Site Type F: The sites in which knife-shaped blades including the Ohwatari type were produced; these include the Ohwatari-2 site's 1st and 2nd occupational layers.

The site types A and B are assigned chronologically to Stage 1, similar to those of the coastal area. The Nanbukogyodanchinai site of Site Type B is characterized by a large lithic circular concentration. In Chronological Stage 2 of this area, only one site type, Site Type C, is attributed to this middle chronological-cultural period. The characteristics of Site Type $\mathrm{C}$ in this interior region are similar to those of the coastal area-specifically an abundance of Koide-type and Yonegamori-type trapezoids, with only occasional knife-shaped blades - although the size of the chipped stone tools is generally smaller than that of the coastal area. The latest chronological period known as Chronological Stage 3 is represented by sites categorized as Site Type F. In contrast to the previous chronological stage and Chronological Stage 3 sites of the coastal area, these assemblages mainly consist of large blades. 
In the Ohu Mountains area, very few sites show evidence that lithic raw materials were brought from outside to manufacture tools. However, the chipped stone tools in Site Type C (Chronological Stage 2) sites were made from high-quality siliceous shale whose provenance was the coastal area of the Japan Sea, as discussed above. These lithic materials were transported more than $90 \mathrm{~km}$ into the Ohu Mountains area. In contrast, lithic materials of those site types other than Site Type C were likely procured nearby, based on my visual observation of dorsal cortex, texture, and color of the lithic artifacts in the assemblages.

The technological characteristics of each site type are similar to those of the coastal area. Despite the similarities, differences in the quality and quantity of siliceous shale available contrasts significantly between the areas, which may have influenced the characteristics of the assemblages. In Chronological Stage 1 of the Ohu Mountains area, the circular lithic concentrations correspond with locations in which blades were produced, but no trapezoids are present in the assemblages, while this pattern is reversed in the coastal area. In Chronological Stage 2, the size of lithic artifacts in the Ohu Mountains assemblages are smaller than that of the coastal area, and the intensity of knife-shaped blade production is remarkably low: They are left to be transported into the sites. The raw materials used for shaping tools were carried from the coastal area. In Chronological Stage 3, trapezoids have disappeared from the assemblages in contrast to those of the coastal area of the same period. The technological effort expended to produce knife-shaped blades has increased intensively. This could reflect changes in food-procurement strategy, which led to a significant expansion of the demand for knife-shaped blades.

The physical environment of lithic resource availability contrasts sharply between the coastal area of the Japan Sea and the Ohu Mountains area. The lithic raw materials in the Ohu Mountains area are abundant, but poor in quality. The site types in this area reflect the specific adaptive strategy employed by these foragers, affected by environmental variables. For example, the altitudes of these two distinct foraging areas may be significant, since the altitudes ASL (above sea level) where EUP sites are distributed range between $25-170 \mathrm{~m}$ in the coastal area of the Japan Sea, while those of the Ohu Mountains area are 104-294 m ASL (Table 1). In turn, these altitudinal differences contributed to differences in the ecological conditions under which groups of foragers searched for food and other resources (Nakazawa 2008). The contrast in land use between the two geographic regions provokes the question of how the Palaeolithic foragers survived in this vast region of the northeastern Japanese Islands, while organizing their mobile territories under different environment conditions.

\section{THE EXPLOITATION OF LITHIC RAW MATERIALS AND ORGANIZATION OF FORAGING TERRITORY}

Based on the characteristics of lithic assemblages examined above (i.e., tool composition, morphology of stone tools, lithic reduction technology, and procurement and consumption of lithic raw materials), I would like to propose that the structure of foraging territories in this region have been reorganized three times during the EUP, correlating with the three chronological-cultural stages (chronological stages 1 to 3 ) discussed above (see Figure 11). These changes involved both the size of the territories exploited and the degree of interaction with other groups through trade. 


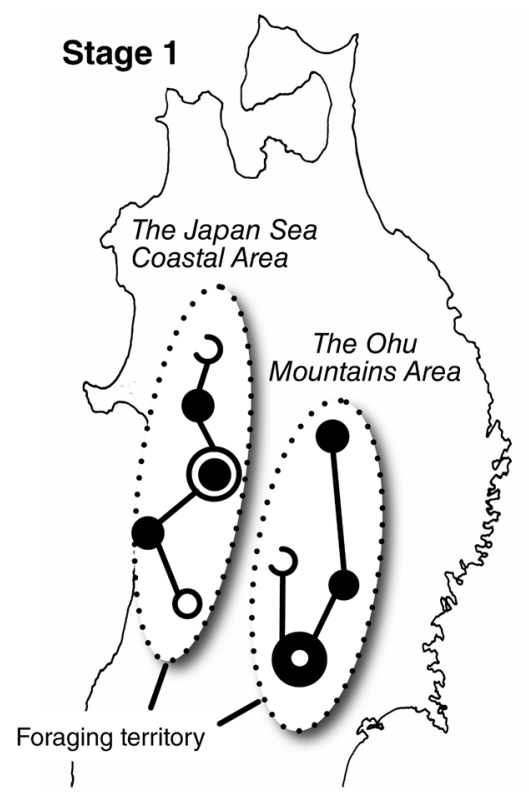

Two different foraging territories (procurement and consumption local raw materials independently)

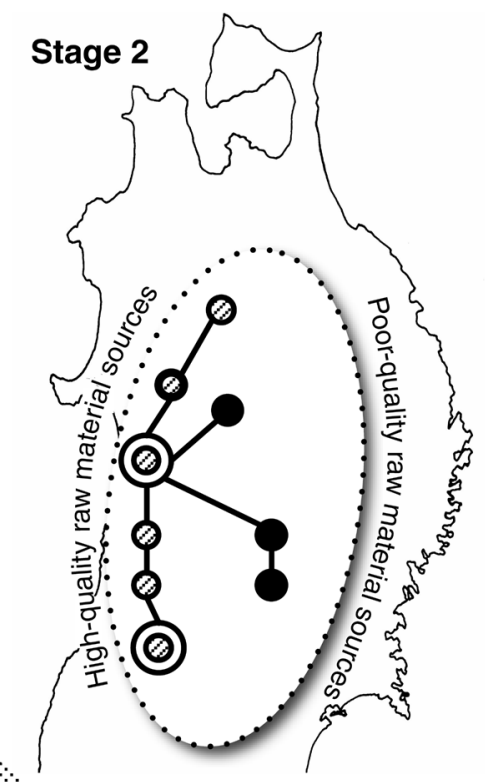

Unification of foraging territory (for procurement high-quality raw materials in the coastal area)

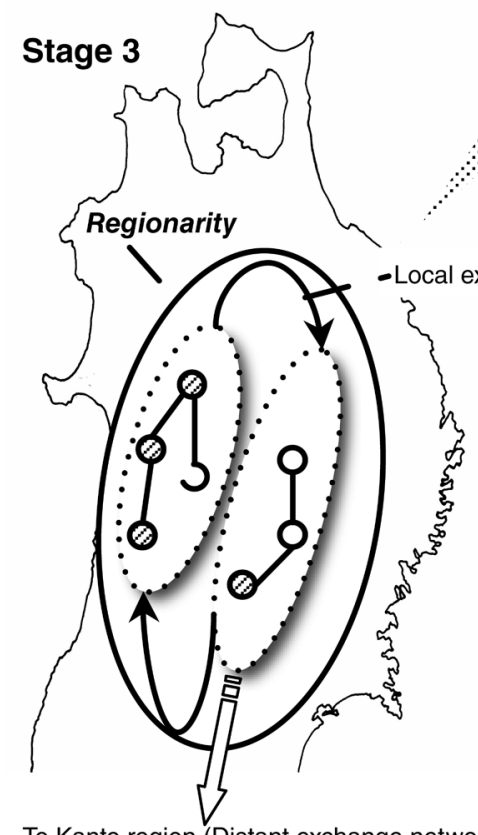

To Kanto region (Distant exchange network?)

\section{Explanatory notes}

Trapezoid production site: site type A

Knife production site: site type $\mathrm{B}$ or $\mathrm{F}$

Knife production site (non-discovery)

(2) Both tools production site: site type $\mathrm{C}$ or $\mathrm{E}$

(a) Lithic circular concentration: site type D (intensive production site)

Lithic circular concentration: site type B (trapezoid production site)

Lithic circular concentration: site type B (blade production site)

Establishment of regionality

(relative to the Kanto region)

Fig. 11. Reorganization of foraging territory in the EUP, northeastern Japan (stages 1 to 3). 


\section{Chronological Stage 1}

In this chronological-cultural phase, trapezoids and knife-shaped blades were produced, used, and discarded in distinctive locations (represented by site types A and B). We cannot recognize any qualitative differences between assemblages, suggesting that Palaeolithic foragers chose these tool classes in response to their functional demands. This functional flexibility is interpreted as a response to varied ecological conditions. Siliceous shale, the locally available material, was exploited both in the coastal area of the Japan Sea and the Ohu Mountains area. It seems that EUP groups independently organized their foraging territories in the coastal area and in the Ohu Mountains area, and that forager groups in each zone specialized in the exploitation of resources within their local environment, with little evidence for economic interaction through trade.

\section{Chronological Stage 2}

In Chronological Stage 2, the knife-shaped blades and the trapezoids were used and discarded in the same sites (site types $\mathrm{C}$ and D). The knife-shaped blades were produced in limited locations, while the trapezoids were produced in all locations. The knife-shaped blades started to be curated, while the trapezoids are used to be more expedient than those of Chronological Stage 1. The difference in tool curation indicates that EUP people put more "value" on knife-shaped blades than during the previous chronological stage. The increased value may have reflected a change in hunting tactics, especially in the use of spears hafted with knife-shaped blades. In addition, abundant high-quality lithic sources found in the coastal area were predominantly exploited. In the Ohu Mountains area, a considerable distance from the coastal area, the size of chipped stone tools in the assemblages became small, and the number of site types significantly more limited than that of the coastal area (there is only Site Type C). I hypothesize that Palaeolithic mobile territories have now become centered in the Japan Sea coastal area. Foraging populations, concentrated in this region, have now expanded their territories to include periodic forays into the mountainous interior to obtain different food resources in spite of their low-quality raw materials for stone tool production. Specifically, the Ohu Mountains area is of limited use for foragers in this chronological stage and is only a short-term occupation area. As a result, foraging territories have shifted to a larger size, including both coastal and mountain areas.

The patterns suggest a unification of foraging territory, but this can result from several different behavioral scenarios. Does it mean that two smaller-scale distinct social groups who are not interacting much and are obtaining resources on their own in Chronological Stage 1, have formed a larger group to exploit both uplands and lowlands in this chronological stage? Or, alternatively, the two once separate groups are now both moving between ecological zones because of demand for high-quality raw materials, or they have started to develop a trade relationship in Chronological Stage 2 that allows them to move stone between the two zones in exchange perhaps for other resources? The former does not seem very likely. Regarding the latter, we do not have enough direct evidence at the moment of exchange or local trade between the coastal area and the mountains in Chronological Stage 2. In addition, we cannot distinguish between two areas by typology and quality of lithic raw materials. Therefore, I would like to accept the second suggestion. 


\section{Chronological Stage 3}

The importance of knife-shaped blades is greatest in Chronological Stage 3 among all the EUP chronological stages. This signifies that foragers have fully incorporated knife-shaped blades as the main hunting weapon in their food-procurement strategies. The size difference of knife-shaped blades between the two areas presumably reflects the difference in the size of animal prey and may reflect resource shifts in this period. Large knife-shaped blades (i.e., the Ohwatari type) in the Ohu Mountains area are often made from locally available siliceous shale, of which source probably because mobile groups needed large nodules for tool manufacture. Foragers started to reorganize their territories. We can recognize two types of knife-shaped blades in both areas: the Shimotsutsumi type in the coastal area and the Ohwatari type in the mountains, while Kazanashidai-type trapezoids disappeared. In this chronological stage, two foraging territories corresponding to the two areas were established, represented by the variation in exploitation of lithic raw materials and food-procurement strategy. However, we found several stone tools made of high-quality siliceous shale in the mountains, while we found a few large knife-shaped blades in the coastal area. These facts imply that foraging groups might have developed an exchange network between the two areas.

\section{CHANGES IN TRAPEZOIDS AND KNIFE-SHAPED BLADES}

I would like to examine the techno-morphological characteristics of the transition from trapezoids to knife-shaped blades during the EUP (Fig. 12). The characteristics of trapezoid retouch techniques changed from flat flaking (Chronological Stage 1) to blunting (Chronological Stage 2), and finally to minute flaking (Chronological Stage 3). The amount of effort expended to retouch trapezoids decreased gradually, but the flat-edge shape was maintained. In addition, the Kazanashidai-type trapezoids retain distinctively shaped haft bases as opposed to the other types which do not have haft bases.

Retouch techniques for knife-shaped blades changed from minute flaking (Chronological Stage 1), to blunting (Chronological Stage 2), to the physical extension of the blunted area on blade edges (Chronological Stage 3). This suggests that the amount of energy investment in tool production increased from chronological stages 1 to 3 . Regarding the edge shapes of knife-shaped blades, the spearhead form is not as pointed as that of the trapezoids in Chronological Stage 1 (this indicates the knife-shaped blade and trapezoid functions are not distinguished clearly). The edge shape was designed to be more pointed in Chronological Stage 2, followed by hafted bases on knife-shaped blades in Chronological Stage 3.

Based on these observations, it seems reasonable to conclude that there is a correlation between trapezoid and knife-shaped blades with respect to investment in tool production and application of retouch techniques. That is to say, the amount of effort expended in trapezoid production was larger than that of knife-shaped blades in Chronological Stage 1, and became equal in Chronological Stage 2 (both trapezoid tools and knife-shaped blades were made by a blunting technique). Ultimately, this further increased effort was invested in the knife-shaped blade production in Chronological Stage 3. This interactively organized technological codependence between the production of knife-shaped blades and trapezoids in lithic assemblages allows us to 


\section{Stage 1}

Stage 2

Stage 3

\section{Trapezoid}
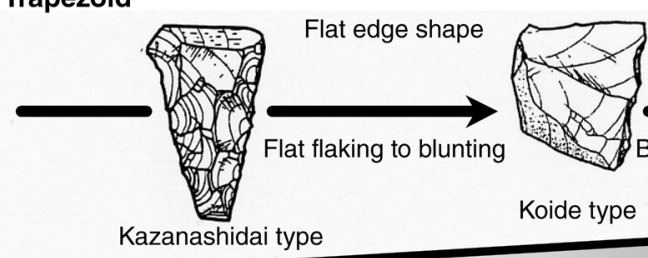

Koide type

Flat edge shape

Limited production to mass production

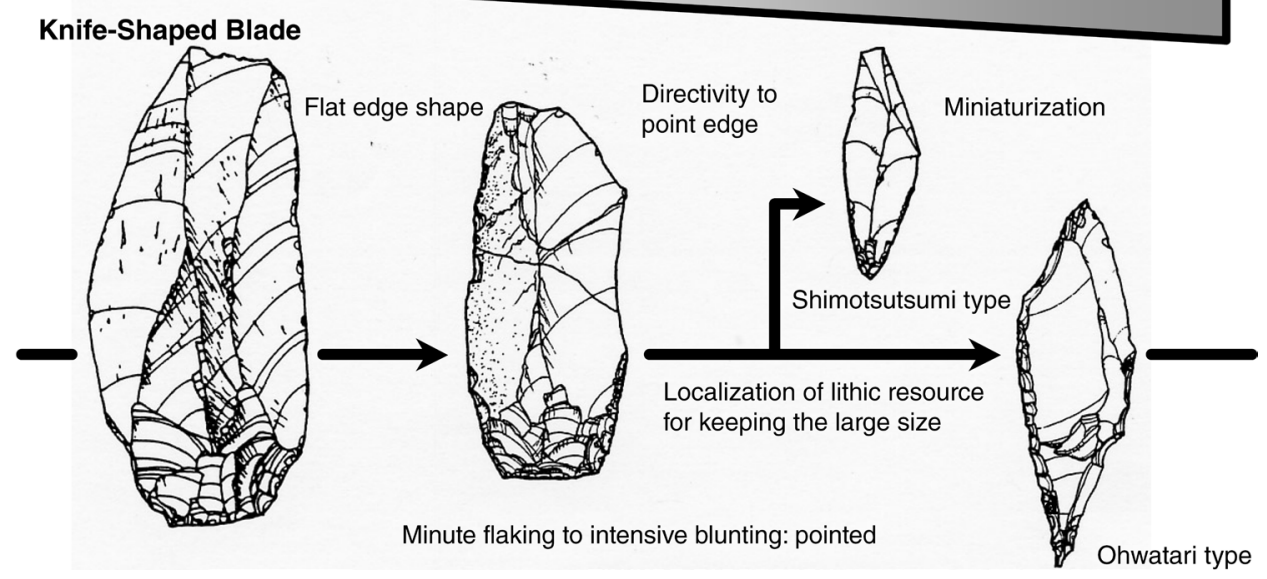

Fig. 12. Hypothesis of morphological change of trapezoids and knife-shaped blades from stages 1 to 3 .

deduce that stone hunting tools as spearheads converged into knife-shaped blades during the process from chronological stages 1 to 3 . With the onset of the late Upper Palaeolithic, only the knife-shaped blades were produced and trapezoids disappeared from the chipped stone components.

In addition, knife-shaped blades and trapezoids shifted from limited production (Chronological Stage 1) to mass production (Chronological Stage 3): a number of refitted specimens in both classes of tools are found among the assemblages of Chronological Stage 3, suggesting that those chipped stone tools were intensively produced. The trapezoids were made on various flake blank forms by minute flaking in Chronological Stage 3, which signifies decreased effort expended in production. The knife-shaped blades were produced in a limited location in chronological stages 1 and 2. However, in Chronological Stage 3, mass production of knife-shaped blades is also recognized in the miniaturizing of the total size of blades in the assemblages of the Japan Sea coastal area, while local lithic raw materials are abundantly used in the assemblages of the Ohu Mountains area. The difference of knife-shaped blade size between the two areas probably reflects the different composition of animal prey in these different ecological environments.

The technological changes in hunting tools of EUP assemblages were tied to changes in procurement and consumption of lithic materials and food resources, and these changes in adaptive strategies are shown in the reorganization of foraging territories. 


\section{CONCLUSIONS}

This article discusses the processes that contributed to the reorganization of foraging territories by hunter-gatherer groups during the EUP across northeastern Japan. Reorganization of foraging territory appears to be caused by a complex relationship between changes in food-procurement strategies, availability of sources for lithic material, and lithic technological organization.

While this synthesis of the evidence did provide insights into these dynamic processes of forager adaptation and change in the EUP, there remain a few significant issues and shortcomings. First, researchers must find ways to elucidate subsistence activities through actual food remains rather than food-procurement and processing technologies. Activities associated with food procurement are difficult to fully understand because of the absence of faunal remains in the archaeological sites that have been examined and sites elsewhere. It is a significant challenge to explore new research strategies for the investigation of Palaeolithic subsistence in the Japanese Islands, particularly given these severe problems of preservation of organic remains in many regions.

Secondly, more accurate techniques of source provenance for siliceous shale and other poorly studied raw materials need to be developed. In the research reported, like many local lithic analysts in Japanese archaeology, I relied on distinctions between siliceous shale provenances in the Japan Sea coastal area and the Ohu Mountains area that are simply based on empirically recognized visual characteristics. To achieve more accurate lithic source analysis, we need to establish more precise and objective analytical methods for sourcing difficult materials like siliceous shale, allowing more detailed reconstruction of lithic procurement routes and hence zones of forager movement defining territories.

Finally, comparative studies with other areas need to be actively conducted to broaden our understanding of regional similarities and differences in EUP mobility strategies and territories. In particular, I expect that assemblages in the Ohu Mountains area have a close technological relationship to those of the Kanto region after Chronological Stage 3. Knife-shaped blades that exhibit a strong resemblance to the Ohwatari type have been found in the Shimousa Plateau in the southern Kanto region. Chipped stone tools in the Kanto region were mainly made of obsidian obtained from long-distance sources, as well as locally available chert, during Chronological Stage 3. However, siliceous shale for lithic raw material has been transported from northeastern Japan to the Simousa Plateatu in the southern Kanto region. After the onset of Chronological Stage 3, it seems that the "regionality" of Palaeolithic societies was emerging and more complex ways of lithic raw material exploitation (e.g., exchange) were employed in east Japan (i.e., between the Tohoku and Kanto regions: Fig. 11). The final period, Chronological Stage 3, seems to reflect an attempt to develop and expand forager trade networks to the south Kanto region. During this period, we can find the Aira-Tanzawa tephra in a lot of sites all around the Japanese Islands. The Aira volcanic eruption happened approximately 23,000 years ago in the southern Kyusyu region. This disaster might have caused serious environmental fluctuations, and the foragers would have needed to construct solid alliance relationships and develop trade networks over a vast area to obtain social and material resources.

In this article, I focused on the lithic raw material exploitation and the organization of foraging territories among Palaeolithic groups in northeastern Japan. A conse- 
quence of my multifaceted approach to the issue is that I was able to document the mutual relationship between the establishment of food-procurement strategies dependent heavily on the technology of knife-shaped blades and the appearance of certain types of Palaeolithic mobile territories between EUP chronological stage 1 to 3 . Future research will provide more specific evidence and more general comparative perspectives, to help us understand more about the northeastern Japanese Palaeolithic foragers who developed tool stone technologies heavily reliant on the use of siliceous shale, which in turn will help to illuminate the adaptive variation among the Paleolithic hunter-gatherers in various environments of the Japanese Islands.

\section{ACKNOWLEDGMENTS}

I thank the following individuals for their thoughtful and valuable comments on this article: Masao Anbiru, Toshio Yanagida, Takao Shibuya, Emiko Ishikawa, Sadakatsu Kunitake, Takashi Suto, Kazuki Morisaki, Kazuhiko Kanda, Hiroshi Yoneda, Kenshi Ohno, Yasutoki Togashi, Kyoichi Kikuchi, Kazuharu Igarashi. I also would like to thank Yuichi Nakazawa for helpful suggestions, translation, and constant support.

\section{REFERENCES CITED}

ANDREFSKY, WiLLIAM, JR.

1994 Raw material availability and the organization of technology. American Antiquity 59:21-35.

2009 The analysis of stone tool procurement, production, and maintenance. Journal of Archaeological Research $17: 65-103$.

BINFORD, LEWIS R.

1977 Forty-seven trips, in Stone Tools as Cultural Makers: 24-36, ed. R.S.V. Wright. Canberra: Australian Institute of Aboriginal Studies.

Fujiwara, Hitoshi, and Toshio Yanagida

1991 The aspect of Hokkaido and Tohoku region. Lithic Culture Research 3:151-163 (in Japanese).

Hata, AKISHige

1998 Siliceous shale and its distribution. The Archaeological Journal 432:31-35 (in Japanese).

Kunitake, Sadakatsu

2005 The change of settlement behavior and technological structure in the early Upper Paleolithic. Material Culture 78:1-25 (in Japanese).

Jones, G. T., E. Beck, E. Jones, And R. E. Hughes

2003 Lithic source use and Paleoarchaic foraging territories in the Great Basin. American Antiquity $68: 5-38$.

Larson, Mary Lou, and Marcel Kornfeld

1997 Chipped stone nodules: Theory, method, and examples. Lithic Technology 22:4-18.

NaKazawa, Yuichi

2008 Human resource use during the Upper Palaeolithic in Cantabria, northern Spain. The Archaeological Journal: 19-22 (in Japanese).

Oda, Shizuo

1969 Some aspects of the Japanese Preceramic Age: The microlithic tendency in the southwestern part of Japan. Anthropological Science 77-5/6:224-245.

1977 On the trapezoids. Material Culture 18:1-13 (in Japanese).

Oda, Shizuo, and Charles T. Keally

1979 Japanese Palaeolithic Cultural Chronology. International Christian University Archaeological Research Center.

Riel-Salvatore, Julien, and Michael C. Barton

2004 Late Pleistocene technology, economic behavior, and land-use dynamics in southern Italy. American Antiquity 69:257-274. 
Sato, Hiroyuki

1988 Problem in the study of trapeze-shaped tools. Archaeological Journal 73-3:1-37 (in Japanese).

1992 The Structure and Evolution of Japanese Palaeolithic Culture. Kashiwa Shobo (in Japanese).

Serizawa, Chosuke

1978 The stone age of Japan. Asian Perspectives 19:1-14.

ShaCkLy, M. STEVEN, ED.

1998 Archaeological Obsidian Studies: Method and Theory. Vol. 3 of Advances in Archaeological and Museum Science. New York: Plenum Press.

Sugihara, Sosuke

1956 The Stone Age Culture found at the Iwajuku, Gunma Prefecture, Japan. Report on the Research by Faculty of Literature, Archaeology 1, Meiji University (in Japanese).

Suto, TAKASHI

2007 A reexamination of hunting weapon classification in Japanese Upper Palaeolithic. Palaeolithic Research 3:15-33 (in Japanese).

SuZUKi, JiRo

2001 The aspect of the first half of stage in knife-shaped tools culture. The Achievement of the Sagamino Palaeolithic Chronology: 35-54 (in Japanese).

Tozawa, Mitsunori, Masao Anbiru, Jiro Suzuki, and Kunio Yajima

1974 The Sunagawa Preceramic Site in Saitama Prefecture-Report on the 2nd Research (in Japanese).

Yoshikawa, KoHtaro

2007 The procurement and consumption of raw material and the reorganization of nomadic sphere in Japanese Upper Palaeolithic period. Palaeolithic Research 3:35-58 (in Japanese).

2008 The exploitation of raw material in prehistoric northeastern Japan. The Archaeological Journal 575:23-27 (in Japanese).

\section{ABSTRACT}

This paper explores the organization of foraging territories of populations in early Upper Palaeolithic northeastern Japan. First, a chronology is established for the region, outlining three stages known as chronological stages 1 to 3 . This is followed by a discussion of the role of trapezoids and knife-shaped blades, lithic raw materials (especially locally available siliceous shale), and their environments in understanding lithic technology, food procurement strategies, and lithic resource exploitation in each chronological stage. Various site types are categorized by examination of tool composition, procurement and consumption of foods, and lithic raw materials in each site. The results of this analysis indicate that foraging territories have been reorganized three times, corresponding with each chronological stage. Transformations in foraging territories are associated with changing tool types, lithic technology, exploitation of lithic raw materials, and food procurement strategies, representing the adaptation of human populations to environmental fluctuation in early Upper Palaeolithic. KeYwords: Palaeolithic, Japan, lithics, raw materials, foragers, territoriality, trapezoids. 